\title{
Effect of Stress-Induced Martensite Stabilization on Acoustic Emission Characteristics and the Entropy of Martensitic Transformation in Shape Memory $\mathrm{Ni}_{51} \mathrm{Fe}_{18} \mathrm{Ga}_{27} \mathrm{Co}_{4}$ Single Crystal
}

\author{
Nora Mohareb Samy ${ }^{1}$, Lajos Daróczi ${ }^{1}$, László Zoltán Tóth ${ }^{1}$, Elena Panchenko ${ }^{2}{ }^{\circledR}$, \\ Yury Chumlyakov ${ }^{2}$, Nikita Surikov ${ }^{2}$ and Dezső László Beke ${ }^{1, *(1)}$ \\ 1 Department of Solid State Physics, University of Debrecen, P. O. Box 400, H-4002 Debrecen, Hungary; \\ noramohareb88@gmail.com (N.M.S.); lajos.daroczi@science.unideb.hu (L.D.); \\ toth.laszlo@science.unideb.hu (L.Z.T.) \\ 2 Siberian Physical Technical Institute, Tomsk State University, 634050 Tomsk, Russia; \\ panchenko@mail.tsu.ru (E.P.); chum@phys.tsu.ru (Y.C.); surikov.nick@gmail.com (N.S.) \\ * Correspondence: dbeke@science.unideb.hu
}

Received: 18 March 2020; Accepted: 16 April 2020; Published: 21 April 2020

\begin{abstract}
Simultaneous differential scanning calorimetry, DSC, and acoustic emission, AE, measurements were carried out for single crystals of quenched and stress-induced martensite stabilized (SIM-aged) shape memory $\mathrm{Ni}_{51} \mathrm{Fe}_{18} \mathrm{Ga}_{27} \mathrm{Co}_{4}$ alloy. The transformation temperatures were shifted to higher values, the forward (from austenite to martensite) and reverse transitions became sharper and the width of the hysteresis increased in the SIM-aged sample. The energy distributions of acoustic hits showed similar behaviour to those of the quenched sample and the energy exponents, characterizing the power law behaviour, were also similar. For SIM-aged alloys at heating, in accordance with the sharper (burst-like) transition observed in the DSC run, few high-energy solitary hits were observed, and these hits did not fit to the energy distribution function fitted for smaller energies. Thus, these high-energy events were attributed to high sudden jumps in the phase transition during heating. The effect of long-range order (by applying a heat treatment at $573 \mathrm{~K}$ for $6 \mathrm{~h}$ to transform the B2 austenite to ordered $\mathrm{L}_{1}$ structure) and the SIM-aging on the transformation entropy was also investigated by DSC. It was found that the entropy was about $36 \%$ smaller after SIM-aging of the quenched sample and it was practically unchanged after austenite stabilization.
\end{abstract}

Keywords: shape memory alloys; stress-induced martensite stabilization; acoustic emission; transformation entropy

\section{Introduction}

It is known that martensite stabilization heat treatments, under uniaxial stress, large enough to produce a single variant martensite in shape memory alloys, by aging at temperatures allowing atomic diffusion (stress-induced martensite stabilization, SIM) result in stabilization of the martensite [1-12]. While this stabilization, which can be understood on the basis of the so-called symmetry conforming short-range ordering process $[5,13,14]$, plausibly causes a shift of transformation temperatures to higher values, significant improvement of the shape memory functional properties was also achieved [1-12]. For instance, it was demonstrated in [1] that martensite aging offers a general concept for the production of high temperature actuator materials, and the authors of [1] introduced a new class of high-temperature ferromagnetic shape memory alloys by choosing $\mathrm{Co}_{49} \mathrm{Ni}_{21} \mathrm{Ga}_{30}$ alloy as a model material. In [6], it was shown that SIM aging can result in a large reversible two-way shape memory 
behaviour in $\mathrm{Ni}_{49} \mathrm{Fe}_{18} \mathrm{Ga}_{27} \mathrm{Co}_{4}$ single crystal, and similar results were published, e.g., on NiMnGa [9] and $\mathrm{Co}_{49} \mathrm{Ni}_{21} \mathrm{Ga}_{30}$ [15] and CoNiAl [8] alloys. Thus, in order to reach high-deformation strains (close to the theoretical limits), due to the shift of the transformation temperatures to higher values and the stabilization of the two-way shape memory properties, high-temperature, high-strength ferromagnetic shape memory alloys were developed [1,4,5,8,9]. In a very recent paper [10], it was shown that in $\mathrm{Ni}_{51} \mathrm{Fe}_{18} \mathrm{Ga}_{27} \mathrm{Co}_{4}$ single crystal not only a two-way shape memory behaviour (with a reversible tensile strain of $9 \%$ ) was achieved by SIM-aging but giant rubber-like behaviour was also observed up to $15 \%$, during reorientation of martensite variants. This exceeded by about a factor of two, the maximum compression transformation strain during the B2-L1 $1_{\mathrm{o}}$ martensitic transformation, and thus, it is very attractive for applications in different actuators. In addition, it was also found that in NiFeGaCo alloys, depending on the content and on the stabilization thermal treatments, martensitic transformations between any magnetic state of austenite and martensite can be achieved (see e.g., as a review, [16]), which can be important in tailoring magnetocaloric properties. In these alloys, stabilization thermal treatments of the austenite and martensite phases can also result in a change of the transformation entropy.

It is clear that such SIM-aging, giving preference to a certain martensite variant, should have important effects on the details of the martensite/austenite transformation. It is already documented in papers on the SIM-aging effect (see e.g., [1,9]) that after SIM-aging not only the transition temperatures were shifted to higher values, but the transitions also became sharper: frequently burst-like sharp transitions were observed $[9-11,17,18])$, and the sample can even suffer a macroscopic jump upon heating. However, no systematic investigations, like those suggested by Kustov et al. [19], on the shift and change of the width of the transitions were carried out. Thus, in our paper, we report comparative investigations of the martensitic transformation in SIM-aged and quenched (not SIM-aged) single crystalline shape memory $\mathrm{Ni}_{51} \mathrm{Fe}_{18} \mathrm{Ga}_{27} \mathrm{Co}_{4}$ crystals carried out using differential scanning calorimetry, DSC, and acoustic emission, AE, measurements. Acoustic emission measurements provide interesting information about the details of the jerky character of the transformation and thus about the microscopic details of the structural changes [20].

Special emphasis was given to the question: does the transformation entropy change or not after SIM-aging. Although, based on the arguments published in $[12,19,21]$, it is expected that the entropy does not change due to the stabilization of martensite or austenite. On the contrary, it was concluded in [22] (on the basis of results, obtained in Cu-Zn-Al shape memory alloys) that "it would be improper to assume in any model that the entropy of transformation remains unchanged after specific thermal treatments which lead to stabilization ... ". Indeed, it was shown that the entropy increased in austenite stabilized sample (by about $4 \%$ ) and decreased after martensite stabilization (by about $12 \%$ ) [22]. This question, which was not investigated in recent high temperature, high-strength ferromagnetic shape memory alloys, is also addressed.

\section{Materials and Methods}

An ingot of the $\mathrm{Ni}_{51} \mathrm{Fe}_{18} \mathrm{Ga}_{27} \mathrm{Co}_{4}($ at $\%)$ alloy was prepared using vacuum induction melting. The single crystals were grown by the Bridgman method in a helium atmosphere. The samples (with dimensions of $3 \mathrm{~mm} \times 3 \mathrm{~mm} \times 6 \mathrm{~mm}$ ) were annealed at $1373 \mathrm{~K}$ for $1 \mathrm{~h}$ at temperatures above the order-disorder transition temperature $(\mathrm{T}=923-973 \mathrm{~K})$ and then water quenched to $\mathrm{T}=293 \mathrm{~K}$ (quenched samples). The B2 high temperature phase of the quenched crystals undergoes to a martensitic transformation to the $\mathrm{L} 1_{0}$-martensite.

The SIM-aging was performed using Instron VHS 5969 testing machine (Instron, Norwood, MA, USA), with a nominal $1 \times 10^{-3} \mathrm{~s}^{-1}$ strain rate [10]. The sample was undergone to compressive stress-induced forward martensitic transformation at $423 \mathrm{~K}$, and it was followed by a heat treatment at this temperature, under $400 \mathrm{MPa}$ compressive stress, for $1 \mathrm{~h}$ along the [110]B2||[100]L10 direction (SIM-aged sample). 
Heat treatments for stabilizing the austenite, by initiating a B2/ordered $\mathrm{L} 2{ }_{1}$ transformation in the austenitic state below the order/disorder temperature $(\mathrm{T}=923-973 \mathrm{~K}$ [23]), were performed at $573 \mathrm{~K}$ for $6 \mathrm{~h}$, in order to reach a highly ordered $\mathrm{L} 2{ }_{1}$ phase.

The calorimetric measurements and their evaluations were carried out, similar to the usual procedure described in Refs. [24-27]. The mass of the quenched and austenite-stabilized samples was $385 \mathrm{mg}$, while it was $18 \mathrm{mg}$ for the SIM-aged sample. The DSC measurements were carried out with a Perkin Elmer DSC 7 device (PerkinElmer Inc., Waltham, MA, USA), using 10 K/min driving rate. The calibration was made with the melting point of ice as well as pure indium. The time constant of the device was found to be $6 \mathrm{~s}$. This value was taken into account in the calculation of the contributions of the decay of the overlapping peaks in the DSC curves [24].

The acoustic emission measurements were carried out in a modified DSC device (the same equipment with a homemade accessory) (using the same $10 \mathrm{~K} / \mathrm{min}$ driving rate) with Sensophone AED 404 Acoustic Emission Diagnostic Equipment (Geréb and Co., Ltd., Budapest, Hungary) with piezoelectric sensor (MICRO-100s from Physical Acoustics Corporation, Princeton Junction, NJ, USA). The microphone has good frequency response between $100 \mathrm{KHz}$ and $1 \mathrm{MHz}$, which is nearly flat in the range between 0.2 and $1 \mathrm{MHz}$ at $-75 \mathrm{~dB}$ in average with a maximum $\pm 10 \mathrm{~dB}$ deviation ( $1 \mathrm{~V}$ reference value). The sensor was coupled to the sample surface via a 15-mm long and of 1-mm diameter steel waveguide (made of 100Cr6 chromium alloyed steel of $\mathrm{C}: \sim 1 \%, \mathrm{Cr}: \sim 1.5 \%$, Mn: $\sim 0.35 \%$ and $\mathrm{Si}: \sim 0.25 \%$ composition in hardened state), in order to provide a thermal isolation from the sample when its temperature was widely varied. The analog-to-digital converter sampling rate was $16 \mathrm{MHz}$, and the setup had a band-pass from $30 \mathrm{KHz}$ to $1 \mathrm{MHz}$. A $30 \mathrm{~dB}$ preamplifier and a main amplifier (logarithmic gain) with $90 \mathrm{~dB}$ dynamic range were used. The threshold level was determined from a measurement carried out in a martensitic state without heating/cooling (i.e., when the low-level acoustic emission should not belong to the phase transformation). The threshold was set to the minimum and then increased until the threshold got up the background noise level. The threshold level determined in this way was then increased by $3 \mathrm{~dB}$ for safety and fixed at $38 \mathrm{~dB}$. For the computation of the exponents, logarithmic data binning (the whole interval was split into 50 bins) was used.

\section{Results}

The results of the DSC measurements, as an illustration, are shown in Figures 1 and 2 for heating and cooling of the quenched and SIM-aged samples, respectively. In the latter case, since the burst-like transformation was accompanied with a large, sudden shape change [10], silicon grease was used to fix the SIM-aged sample into the sample holder of the DSC. It is one of the reasons why the mass of the SIM-aged sample was about twenty times smaller: this helped us to fix the sample. The second reason was that after a few thermal cycles, the sample was broken into small pieces, because of the very large local stresses during transformation. On the smaller samples, no cracking was observed even after many cycles. Of course, the DSC and AE measurements were carried out on the same piece of sample. This size, we believe, did not introduce disturbing scale effects: according to [27] decreasing the size of the sample resulted only in a split of the DSC peaks, at the same cooling/heating rates, but, e.g., the energy distribution of AE events did not essentially change. This was also confirmed by measuring $\mathrm{AE}$ on another piece of the broken sample (with a mass of about three times larger, i.e., with $\mathrm{m}=47 \mathrm{mg}$ ), and besides the increased AE activity, the same characteristic features were obtained. It can be seen (see also Figures 1-3 and Table 1) that the transformation temperatures are shifted to higher temperatures and the transitions are indeed sharper in the SIM-aged sample. In addition, for the SIM-aged sample, the DSC curve split into separate peaks, illustrating a stepwise character of the transformation. Table 1 also shows that the start and finish temperatures, obtained from the DSC and AE data, are in a good agreement with each other, except some acoustic activity during cooling at temperatures higher than the DSC martensite start temperature shown in Table 1 for the SIM-aged sample; see Figures $2 \mathrm{~b}$ and $4 \mathrm{~d}$. This can be related to the higher sensitivity of the AE as compared to the DSC. The heat treatment for austenite stabilization had no detectable effect. 
In Figure 3, the hysteresis loops of the martensitic transformation were constructed from the measured DSC curves. The martensite volume fraction was calculated using the normalized partial integrals of the $\mathrm{Q} / \mathrm{T}$ curves $[25,26]$ ( $\mathrm{Q}$ is the heat of transformation and $\mathrm{T}$ is the temperature), and the value of the entropy, used for normalization, was determined from the measured DSC according to the usual procedure [26].

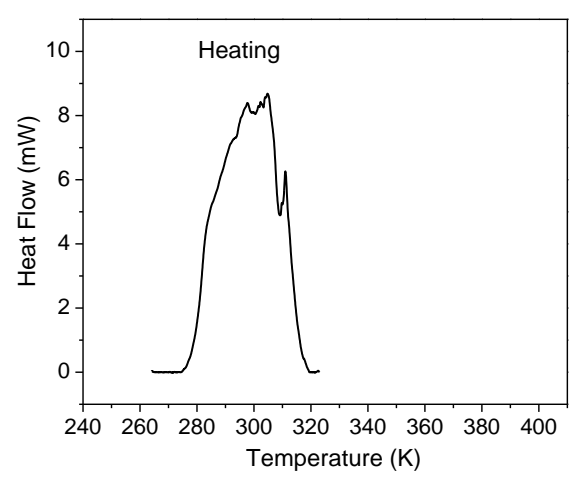

(a)

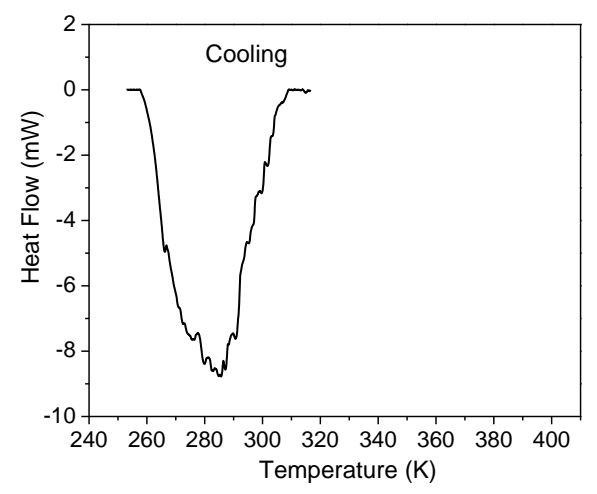

(b)

Figure 1. DSC runs for heating (a) and cooling (b) for the quenched $\mathrm{Ni}_{51} \mathrm{Fe}_{18} \mathrm{Ga}_{27} \mathrm{Co}_{4}$ single crystals.

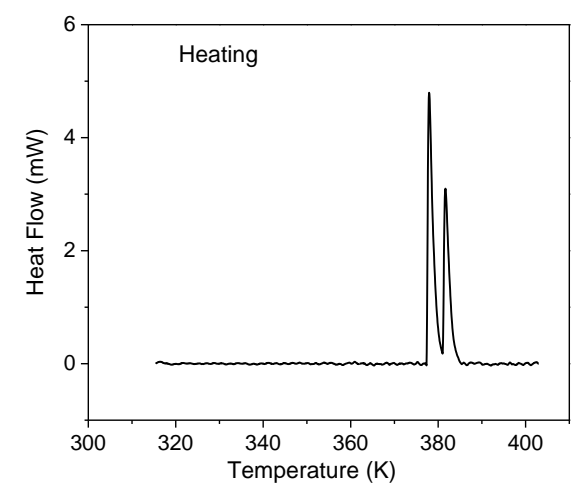

(a)

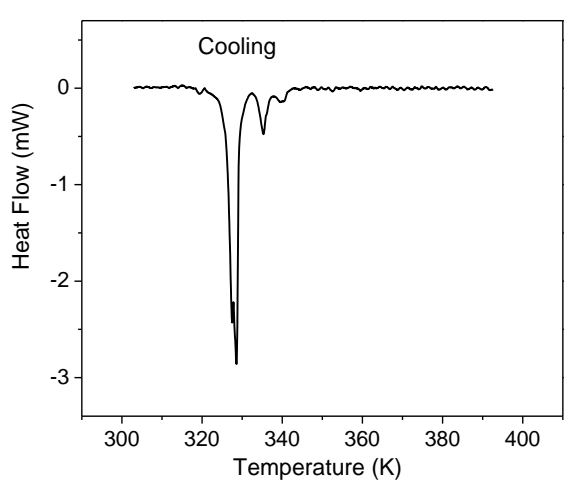

(b)

Figure 2. DSC runs for heating (a) and cooling (b) of the stress-induced martensite stabilized (SIM-aged) $\mathrm{Ni}_{51} \mathrm{Fe}_{18} \mathrm{Ga}_{27} \mathrm{Co}_{4}$ single crystals.

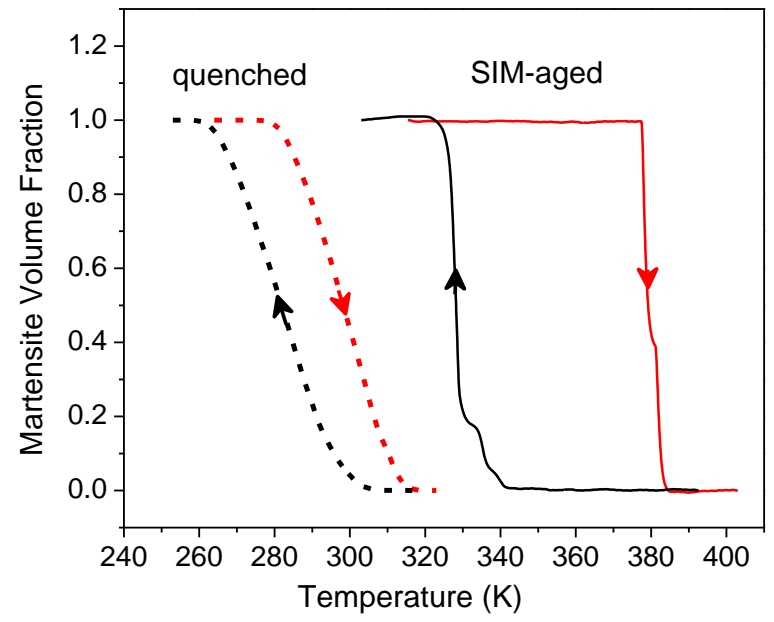

Figure 3. Hysteresis loops calculated from the DSC curves for the quenched and SIM-aged $\mathrm{Ni}_{51} \mathrm{Fe}_{18} \mathrm{Ga}_{27} \mathrm{Co}_{4}$ single crystals $(10 \mathrm{~K} / \mathrm{min})$. 
Table 1. Transition temperatures for the quenched, austenite stabilized and stress-induced martensite stabilized (SIM)-aged $\mathrm{Ni}_{51} \mathrm{Fe}_{18} \mathrm{Ga}_{27} \mathrm{Co}_{4}$ single crystals, as obtained from DSC and acoustic emission (AE) measurements. The error bars are about $\pm 3 \mathrm{~K}$.

\begin{tabular}{ccccc}
\hline Type of Sample & $\mathbf{A}_{\mathbf{S}}$ & $\mathbf{A}_{\mathbf{f}}$ & $\mathbf{M}_{\mathbf{s}}$ & $\mathbf{M}_{\mathbf{f}}$ \\
\hline Quenched, AE & 270 & 337 & 317 & 254 \\
Quenched, DSC & 276 & 320 & 308 & 259 \\
Austenite Stabilized, AE & 270 & 337 & 317 & 254 \\
SIM-aged, DSC & 377 & 386 & 343 & 317 \\
\hline
\end{tabular}

Table 2 shows the calculated values of the transformation entropy. It can be seen that the entropy did not change after austenite stabilization heat treatment. On the other hand, the transformation entropy decreased by about $36 \%$ for the SIM-aged sample.

Table 2. Values of the transformation entropy, $-\Delta s$, calculated from the DSC curves for the quenched, austenite stabilized (annealed at $573 \mathrm{~K}$ for $6 \mathrm{~h}$ ) and SIM-aged $\mathrm{Ni}_{51} \mathrm{Fe}_{18} \mathrm{Ga}_{27} \mathrm{Co}_{4}$ single crystals. The numbers are averaged values for heating and cooling and the error bars are about $\pm 0.08 \mathrm{~J} / \mathrm{mol} \cdot \mathrm{K}$, within which, the values for heating and cooling were also the same.

\begin{tabular}{cccc}
\hline$-\boldsymbol{\Delta} \mathbf{S}$ & Quenched & Austenite Stabilized & SIM-Aged \\
\hline$(\mathrm{J} / \mathrm{mol} \cdot \mathrm{K})$ & 0.94 & 0.94 & 0.60 \\
\hline
\end{tabular}

The measured acoustic signals (at $10 \mathrm{~K} / \mathrm{min}$ rate) for the quenched and SIM-aged samples are shown in Figure 4 (the plots for the austenite stabilized samples are very similar to those obtained in the quenched sample and thus are not shown). It can be seen that the number of AE events for the quenched sample, in accordance with the about 20 times larger mass, is much higher than for the SIM-aged one (see also Table 3, where the numbers of hits, $N$, and the sum of the AE peak energies and the average peak energies for heating and cooling are also given). For the determination of the energy probability distribution functions, the energy of an individual acoustic event, $E_{i}$, can be determined from the integration of the amplitude (voltage, $U_{i}$ ) versus time signal (see Figure 5) [28-30]. Our experimental setup allows the calculation of the energy associated with each individual hit. In our evaluation programme, the $E_{i}=\frac{1}{R} \sum_{j} \frac{U_{i j}^{2}}{2} \tau_{i}$ approximation is used, where $R$ is a reference electrical resistance [28,29] (taken as $1 \mathrm{M} \Omega$ ) and $\tau_{i} \cong \frac{t_{i}}{n_{i}}$, which means that it is assumed that all small separate triangle-shaped peaks (indexed by $j$ in Figure 5) have the same lengths $\left(t_{i}\right.$ and $n_{i}$ denote the duration time and the number of oscillations, respectively, during $t_{i}$ ). The estimated characteristic frequency of the oscillations (using the relation $f=n_{i} / 2 t_{i}$ ) was in the order of $100 \mathrm{kHz}$. It is worth noting that the physics behind the source of AE is still far from being fully understood [28,31], and thus from the information contained in a detected AE signal, it is difficult to recover the information about the source [30]. However, there is a commonly accepted wisdom in the literature that AE provides a suitable measure of the dissipated energy associated with the process from which it originates $[29,30,32]$. This is also confirmed by a very good agreement between the energy exponents calculated from calorimetric and AE measurements [20,32]. 
Table 3. Critical energy exponents, $\varepsilon$, and energies of hits in the acoustic noises for heating and cooling at $10 \mathrm{~K} / \mathrm{min}$ for the quenched, austenite stabilized and SIM-aged $\mathrm{Ni}_{51} \mathrm{Fe}_{18} \mathrm{Ga}_{27} \mathrm{Co}_{4}$ single crystals. $E_{t}$ is the sum of peak energies $\left(\sum_{i} E_{i}\right), E_{a v}$ is the average peak energy $\left(E_{a v}=\frac{\sum_{i} E_{i}}{N}\right.$ and $N$ is the number of hits). The energies are given in $\mu \cdot V^{2} \cdot \Omega^{-1}$ s units.

\begin{tabular}{ccccccccc}
\hline \multirow{2}{*}{ Type of Sample } & \multicolumn{4}{c}{ AE for Heating } & \multicolumn{4}{c}{ AE for Cooling } \\
\cline { 2 - 9 } & $\boldsymbol{N}$ & $\boldsymbol{E}_{\boldsymbol{t}}$ & $\boldsymbol{E}_{\boldsymbol{a v}}$ & $\boldsymbol{\varepsilon}$ & $\boldsymbol{N}$ & $\boldsymbol{E}_{\boldsymbol{t}}$ & $\boldsymbol{E}_{a v}$ & $\boldsymbol{\varepsilon}$ \\
\hline Quenched & 32077 & $6.1 \times 10^{4}$ & 1.9 & $1.84 \pm 0.06$ & 40500 & $1.4 \times 10^{5}$ & 3.6 & $1.87 \pm 0.06$ \\
Austenite Stabilized & 18891 & $9.2 \times 10^{3}$ & 0.5 & $1.97 \pm 0.06$ & 26930 & $4.0 \times 10^{4}$ & 1.5 & $1.94 \pm 0.12$ \\
SIM-aged & 967 & $1.9 \times 10^{6}$ & 1970 & - & 5278 & 1062 & 0.2 & $1.2 \pm 0.1$ \\
$\begin{array}{c}\text { SIM-aged, removing } \\
\text { high energy events }\end{array}$ & 964 & 769 & 0.8 & $1.7 \pm 0.3$ & - & - & - & - \\
\hline
\end{tabular}

The statistical distribution functions of the parameters of $\mathrm{AE}$ signals $\left(U_{i}, E_{i}\right.$ and $\left.t_{i}\right)$, emitted during martensitic transformations, usually follow general power law behaviour $[20,28,29]$

$$
P(E)=C E^{-\varepsilon}
$$

where $E$ is the peak energy of an acoustic event and $\varepsilon$, is the characteristic exponent, and the $C$ prefactor includes normalization and is chosen to be proportional to $\exp \left(-E / E_{c}\right)$, where $E_{c}$ is the cut-off value $[28,29]$. Thus, Figures $6-8$ show the energy distribution functions during heating and cooling for the quenched, austenite stabilized and SIM-aged samples, respectively. It can be seen that these functions can be well approximated by a straight line over three to four orders of magnitude on the energy scale, i.e., we can take that $\exp \left(-E / E_{c}\right) \cong 1$ in the prefactor $C$ (Equation (1)). (In our measurements, the number of hits at higher energies became very low before the cut-off effect would become visible.) The values of the energy exponents are also included in Table 3. The most remarkable difference between the plots for the SIM-aged and quenched samples is that while the characteristic exponents are the same within the error bars in Table 3 (and their values were also the same for heating and cooling), the distribution function for heating in the SIM-aged sample contains high energy solitary $\mathrm{AE}$ hits and these points fall above the straight line fitted to the remaining part of the plot in Figure 8a. It is worth mentioning that the existence of such AE hits was checked by performing eight separate runs: in all cases similar results were obtained, and it was also detected that they appeared not randomly but at the same temperature (see the marked points in Figure 4c). In addition, the average peak energy, $E_{a v}$, after the removal of the last three high energy points, is in the same order of magnitude as the values for the other three cases in Table 3 (compare the $E_{a v}$ values for heating in the SIM-aged sample before and after the removal of the above three points). 


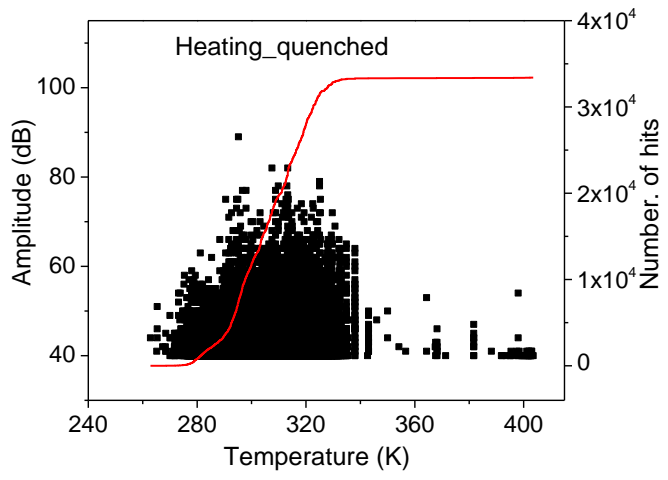

(a)

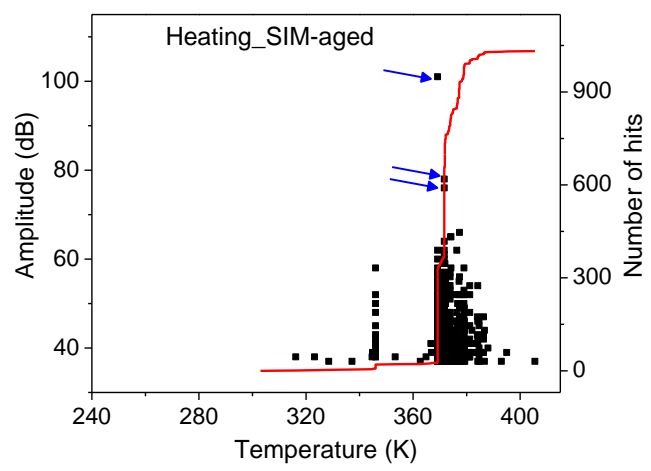

(c)

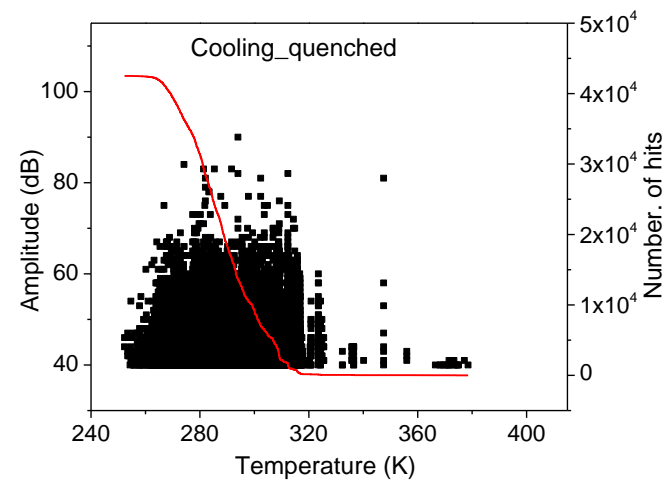

(b)

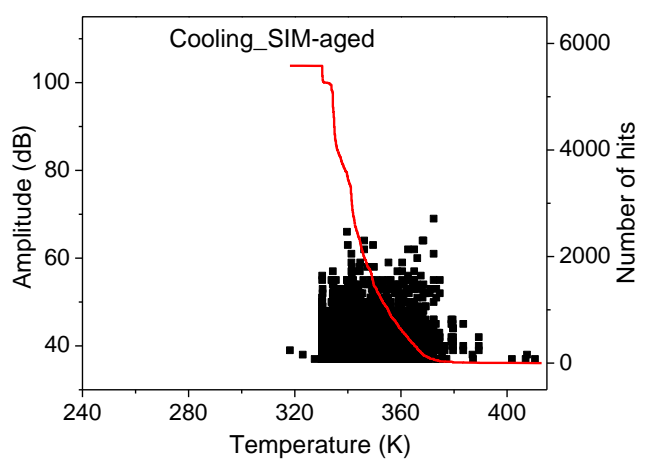

(d)

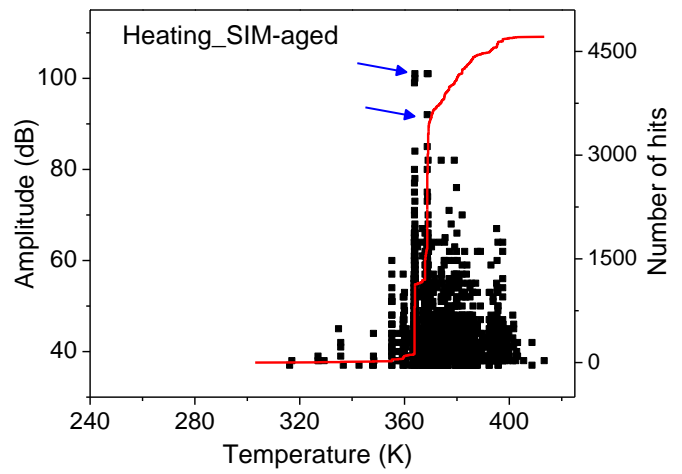

(e)

Figure 4. Acoustic emission signals during the transformation: heating and cooling for the quenched, $(\mathbf{a}, \mathbf{b})$ and SIM-aged (c,d) $\mathrm{Ni}_{51} \mathrm{Fe}_{18} \mathrm{Ga}_{27} \mathrm{Co}_{4}$ single crystals. (Each point corresponds to an acoustic emission (AE) event, and the continuous line, indicating the transition, is the cumulative number of them.) In Figure 4c, the three points, indicated by arrows, show the solitary high energy hits for the sample with $m=18 \mathrm{mg}$ (see also below in Figure 8a), whereas Figure 4e shows the same plot for the SIM-aged sample for heating with $m=47 \mathrm{mg}$. 


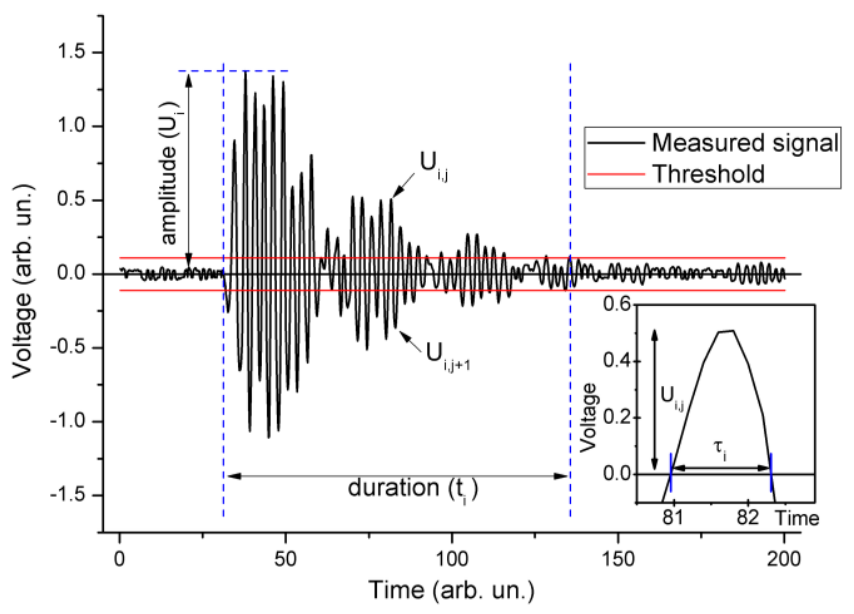

Figure 5. Typical measured signal belonging to one acoustic event with a medium energy. The insert shows one oscillation of the event. The index " $i$ " refers to the number of the AE event, while index " $j$ " refers to the number of oscillations in the $i$-th event, $1 \leq j \leq n_{i}$, where $n_{i}$ is the total number of oscillations for the $i$-th event. $\tau_{i} \approx t_{i} / n_{i}$ (see also the text).

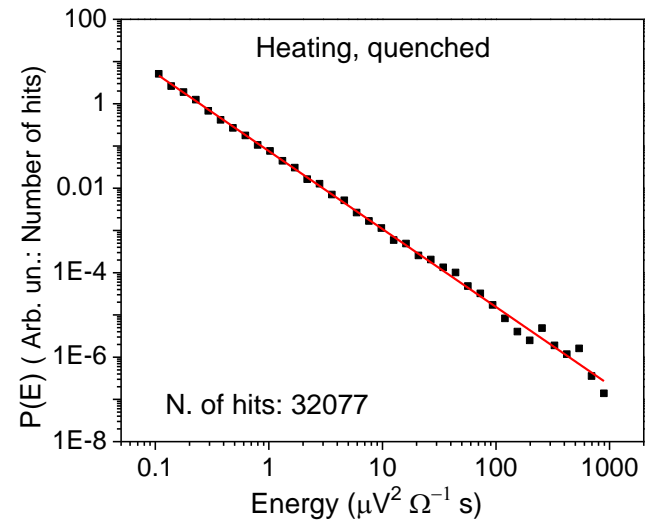

(a)

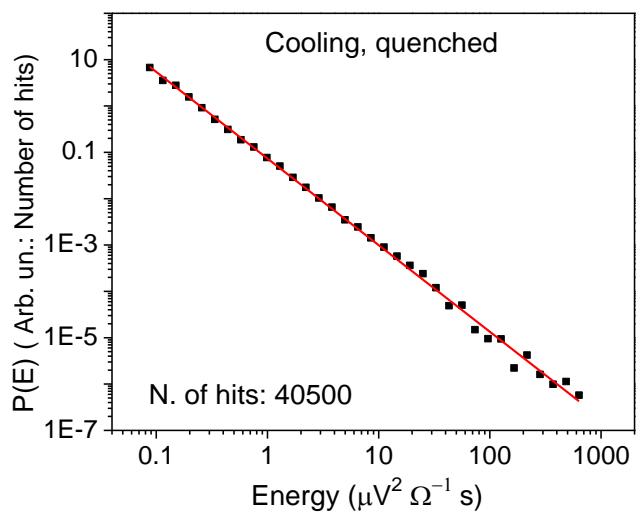

(b)

Figure 6. Energy distribution functions; Log $\mathrm{P}$ versus $\log \mathrm{E}$, obtained from acoustic measurements during heating (a) and cooling (b) in quenched $\mathrm{Ni}_{51} \mathrm{Fe}_{18} \mathrm{Ga}_{27} \mathrm{Co}_{4}$ single crystal.

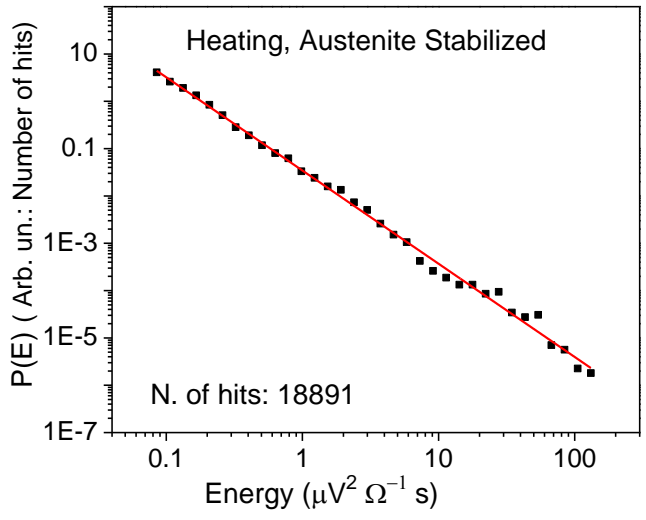

(a)

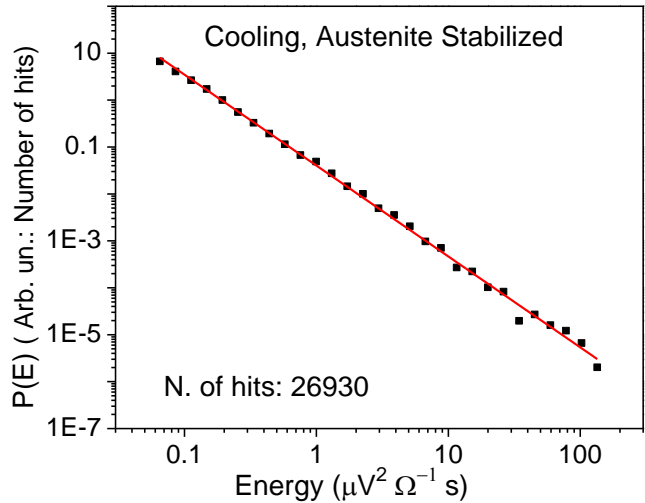

(b)

Figure 7. Energy distribution functions; $\log \mathrm{P}$ versus $\log \mathrm{E}$, obtained from acoustic measurements during heating (a) and cooling (b) in austenite stabilized $\mathrm{Ni}_{51} \mathrm{Fe}_{18} \mathrm{Ga}_{27} \mathrm{Co}_{4}$ single crystal. 


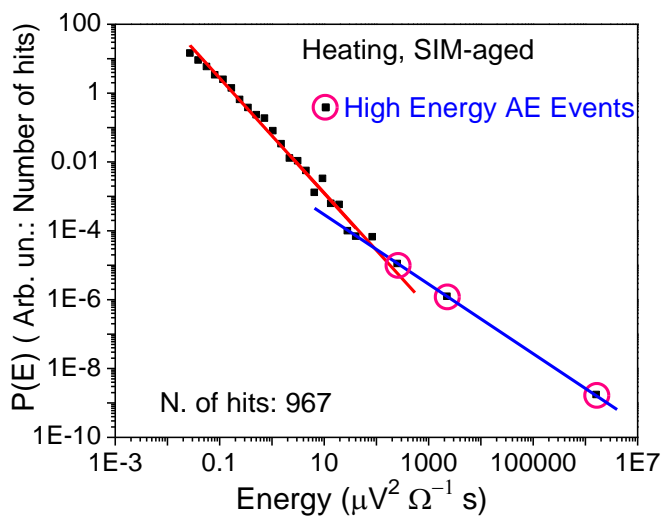

(a)

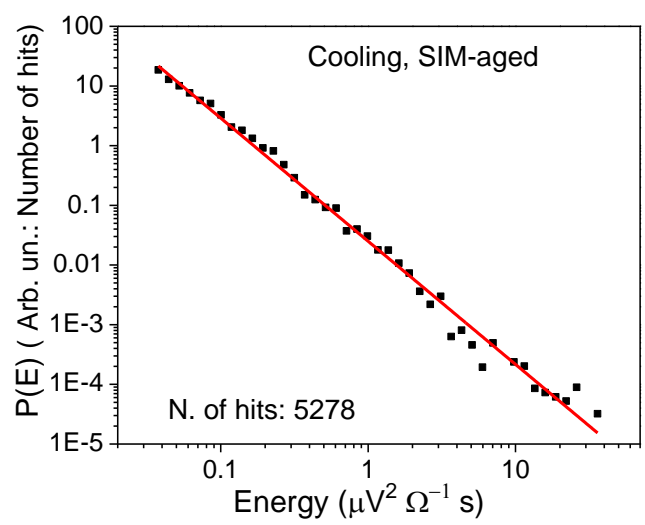

(b)

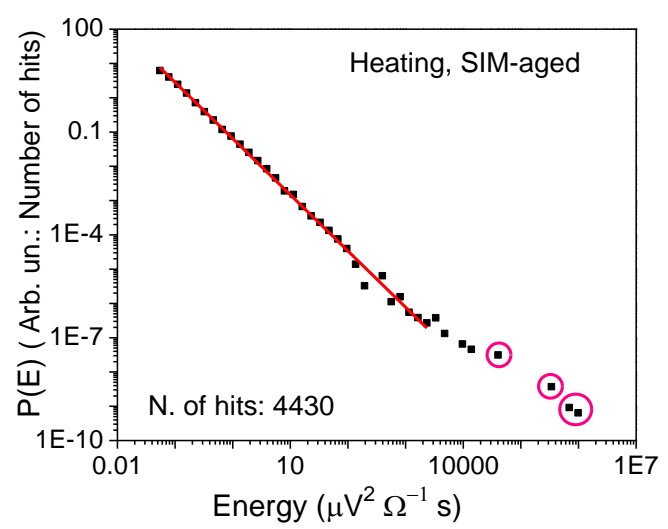

(c)

Figure 8. Energy distribution functions for heating (a) and cooling (b), obtained from acoustic measurements for SIM-aged ( $m=18 \mathrm{mg}$ ) $\mathrm{Ni}_{51} \mathrm{Fe}_{18} \mathrm{Ga}_{27} \mathrm{Co}_{4}$ single crystals. (c) shows, for comparison, the distribution for heating on the SIM-aged sample with $m=47 \mathrm{mg}$ (slopes of the lines, fitted to the first parts, are the same within the error bars).

\section{Discussion}

The results on the hysteresis loops should be compared to the start and finish temperatures (measured also by DSC) and the transformation strain versus temperature $\left(\varepsilon_{t r} \sim T\right)$ plots, published in [11] on the same single crystal after the same heat treatments/SIM-aging. Although in [11] the details of the shape of the hysteresis loop was not determined, the agreement is reasonable; see Figure 9 which, for the illustration of the shift and increase of the width of the hysteresis, shows the schematic hysteresis loops constructed from the data of Table 1 in [11]. Thus, we can conclude that the start and finish temperatures were indeed shifted to higher values, as expected for the martensite stabilization. In addition, according to Figure 3 (and Figure $1 \mathrm{~b}$ in [11]), the cooling transition is less sharp as compared to the heating one.

The value of the transformation entropy can be compared with the value estimated from the Clausius-Clapeyron relation for the temperature dependence of the critical stress, $\sigma_{c r}$ :

$$
\frac{\partial \sigma_{c r}}{\partial T}=-\rho \Delta s / \varepsilon_{\operatorname{tr}}
$$

( $\rho$ is the density and $\varepsilon_{t r}$ is the transformation strain). Figure 10 shows the $\sigma_{c r}$ and $\varepsilon_{t r}$ as the function of $\mathrm{T}$ for the quenched sample as calculated from the $\sigma$ versus $\varepsilon_{t r}$ loops, taken at different temperatures. It can be seen that Figure 10a can be well fitted by a linear function between 350 and $550 \mathrm{~K}$. Although the transformation strain has temperature dependence in (2), since the linear fit is a good approximation 
in Figure 10a, we can use the average value of the transformation strain in this interval (Figure 10b). Thus, using the value of the slope, $d \sigma_{c r} / d T=3.27 \mathrm{MPa} / \mathrm{K}$, and $\varepsilon_{t r} \cong 0.035$, we get $\Delta s=-0.88 \mathrm{~J} / \mathrm{mol} \cdot \mathrm{K}$, which is in a good agreement with the values shown in Table 2.

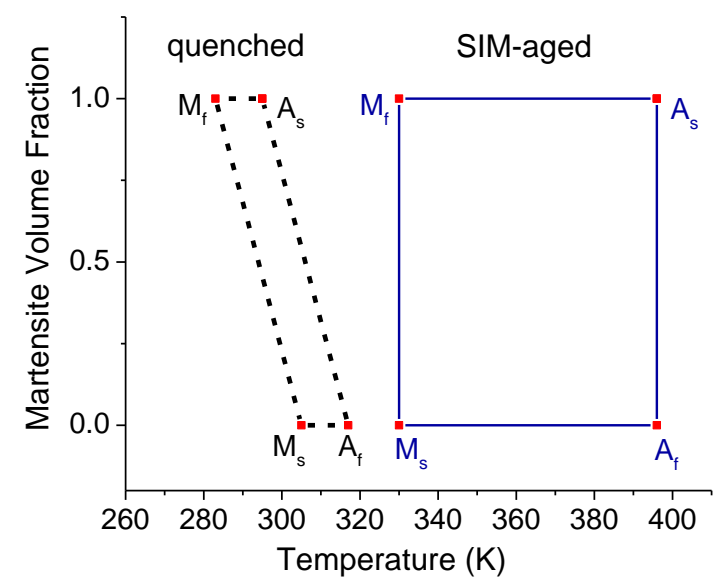

Figure 9. Schematic hysteresis loops from the start and finish temperatures published in [11].

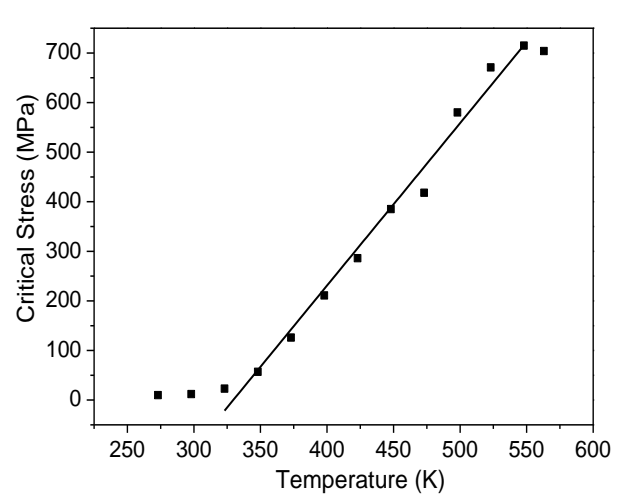

(a)

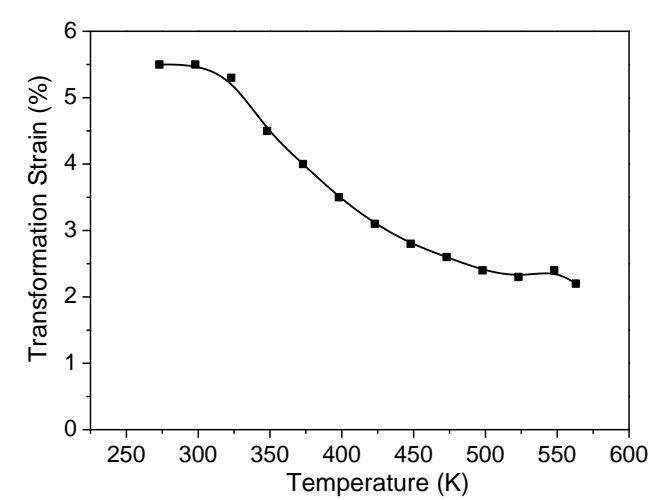

(b)

Figure 10. Temperature dependence of the critical stress (a), the transformation strain (b) for the quenched sample. The solid line in (a) shows the region where the linear fit is a good approximation, while in (b), it is only to guide the eye.

It is clear that the width of the hysteresis increased for the SIM-aged sample. Taking into account that the transformation entropy decreased only by about $36 \%$, the increase of the area of the hysteresis loop by about a factor of 3.5 cannot be attributed only to the entropy change $(\Delta T$, the width of the hysteresis, is inversely proportional to $-\Delta s)$. Thus, the change of the entropy cannot be fully responsible for the above increase, but some additional microscopic dissipative processes have a contribution to this. In [11], it was argued that the stabilization of the detwinned martensite resulted in a significant increase of the dissipated energy (i.e., of $\Delta T$ ), but understanding the details calls for further microscopic investigations. It is worth noting that the increase of the area of the hysteresis cannot be solely interpreted by the increase of the dissipated energy only if the so-called thermoelastic balance is fulfilled. If this is violated, e.g., for the SIM-aged sample (i.e., the magnitude of the elastic energy stored during cooling is different from the relaxed elastic energy during heating), then the contribution of the elastic energies to the area of hysteresis is also not negligible [33]. The results of the AE measurements can give some additional hints in this respect. 
Indeed, the results shown in Figures 6 and 8 and Table 3 are very interesting. While the characteristic energy exponents are the same within the error bar, there are two striking features of the results belonging to the SIM-aged sample:

i. There are high amplitude/energy hits during heating and these fall above the points on the energy distribution function.

ii. Removing these, the energy exponent agrees with the other three values in Table 3 and the average peak energy has similar value to the others.

These findings indicate that some microscopic details of the forward and reverse transformations are different in the SIM-aged sample, which should be related to the burst-like transition. For the sharper heating transition, interestingly, even a few solitary high amplitude/energy AE hits were observed. These belong to the same temperature: see the high, almost vertical jump in the cumulative numbers in Figure 4c. This temperature agrees well with the temperature of the second peak in Figure 2a. It is worth noting that the envelope type DSC curves can be split into small individual peaks using appropriate low heating/cooling rates and/or small investigated masses [27,32,34]. However, we rather attribute the large two peaks in Figure 2a to high velocity sudden jumps of the interface over relatively large distances, resulting in transformation of a considerable amount of martensite volume fraction to austenite.

The energies of the individual acoustic events are directly related to the relaxation (and dissipation) of the energy of elastic waves emitted during an individual jump of the moving austenite/martensite interface $[20,28,30,32]$. Thus, the few large energy events belong to jumps of high velocity, since it is generally accepted that the amplitude of an AE signal is proportional to the interface velocity $[20,28,30,35]$ and $E_{i}$ is proportional to square of the amplitude, $U_{i}$. Nevertheless, the fact that the characteristic exponents are almost the same for both types of samples and in both directions is a strong indication of the robustness of the power law behaviour and calls also for further measurements and microscopic modelling. The above results remind of the effect observed in [36], where stress drops and $\mathrm{AE}$ during mechanically induced motion of twin boundary motion (type I boundary in $\mathrm{Ni}_{2} \mathrm{MnGa}$ ) were measured. It was obtained that the stress drop events were accompanied with single dominant AE signals, while $98 \%$ of the AE signals were emitted during the intervals where no stress drop was happening. The latter signals followed nice power law behaviour, while those associated with stress drops displayed a distribution with a peak (i.e., they did not fit to the curve corresponding to the power law).

The results on the effects of austenite stabilization indicate that the change of the long range order from $\mathrm{B} 2$ to ordered $\mathrm{L} 22_{1}$ of the austenite structure has no detectable effect: the shift of the hysteresis and the change of the transformation entropy was within the limits of experimental error and the energy exponents are also similar for austenite stabilized and quenched samples, although the exponents are a little bit larger for the austenite stabilized sample (Table 3). It can be noted that in [37] differential scanning calorimetric measurements in three polycrystalline ferromagnetic shape memory alloys with compositions $\mathrm{Ni}_{53.5+x} \mathrm{Fe}_{19.5-x} \mathrm{Ga}_{27.0}(x=0,0.5$ and 1.5) were carried out, investigating the effect of the degree of $\mathrm{L} 2_{1}$ order by quenching from different temperatures. It was observed, as expected, that the transformation temperatures were increased/decreased with decreasing/increasing $\mathrm{L} 2{ }_{1}$ order, but the transformation entropy was not determined.

Regarding the change of the transformation entropy, we can conclude that our results are in a good agreement with the results of [22], where a minor increase (about $4 \%$, which was close to the error bar) for the austenite stabilization and about a $12 \%$ decrease for martensite stabilization was observed. Nevertheless, the observed increase of the width of the hysteresis indicates that the entropy change cannot be connected with this since it alone would cause a much smaller effect. It is worth adding that in ferromagnetic shape memory alloys, there is a magnetic contribution to $\Delta s[16,34,37,38]$ and its possible change due to SIM-aging calls for further investigations. It can be added that since the transformation entropy can be sensitive to the changes in the atomic and magnetic order [16], 
it can be assumed that SIM-aging can have a similar effect as the change of the slope of free energy versus the temperature. Regarding the possible contribution of the change of the elastic energy to the entropy change, we remind that after a few thermal cycles, the SIM-aged sample was broken into small pieces because of the very large local stresses due to the large shape change accompanied with the transformation. If the material would not be brittle, this would lead to a small stress accumulation since in our case, the strain, accompanied with the shape change, is close to the expected maximal strain. Thus, in the broken sample, during cycling, this can also cause only a small, sudden change of the elastic energy. In the quenched sample, due to the presence of different twins, the elastic energy (accumulated during cooling and relaxed during heating) should be larger. On the other hand, since the temperature dependence of the elastic constants is usually weak, these different elastic energies represent a negligible contribution to the slopes of the free energies versus the temperature functions of the austenite and martensite, the difference of which is the measure of the entropy change. In addition, it seems to be less probable that defects introduced by the SIM aging would be responsible for the observed entropy change: the martensite stabilization results in more ideal martensite microstructure as compared to the one in the quenched state (e.g., by annealing out of the frozen-in vacancies by quenching). This assumption is also in accordance with the arguments used in [16]: "the only effect of such stabilization is a homogeneous decrease of the chemical free energy of the sample's material". On the other hand, the fact that the austenite stabilization has a minor effect is in accordance with arguments published in $[12,19,22]$, i.e., the change of the long-range order in the austenite, after the heat treatments applied, has a moderate effect in this alloy too.

\section{Conclusions}

SIM-aging caused a shift of transformation temperatures to higher values, and the forward (from austenite to martensite) and reverse transitions became sharper, while the width of the hysteresis increased.

- The energy distributions of acoustic hits in SIM-aged samples showed similar behaviour to those of the quenched sample, and the energy exponents characterizing the power law behaviour were also similar.

- For heating, in accordance with the sharper transition observed in the DSC run, few high amplitude/energy solitary hits were observed, and these points did not fit to the energy distribution function fitted at smaller energies. Thus, these high-energy events were attributed to high sudden jumps in the phase transition during heating. These high, almost vertical jumps, in the cumulative numbers in Figure 4c, agreed well with the temperature of the second DSC peak in Figure 2a. Thus, we attributed the few large energy jumps to jumps of high austenite/martensite interface velocity; this velocity can be orders of magnitude larger than the other velocities with which the interface moves in the quenched sample.

- It was found that the transformation entropy was about $36 \%$ smaller for the SIM-aged sample and was practically unchanged after austenite stabilization.

Author Contributions: Conceptualization, D.L.B., E.P. and Y.C.; methodology, L.D.; software, L.Z.T.; formal analysis, N.M.S.; investigation, N.M.S. and N.S.; writing-original and draft preparation, D.L.B., E.P. and Y.C.; supervision, D.L.B. All authors have read and agreed to the published version of the manuscript.

Funding: This work was supported by the GINOP-2.3.2-15-2016-00041 project. The project was co-financed by the European Union and the European Regional Development Fund. The described research was also supported through the National Research, Development and Innovation Office-NKFIH K119566 project.

Conflicts of Interest: The authors declare no conflict of interest. The funders had no role in the design of the study; in the collection, analyses, or interpretation of data; in the writing of the manuscript or in the decision to publish the results. 


\section{References}

1. Niendorf, T.; Krooß, P.; Somsen, C.; Eggeler, G.; Chumlyakov, Y.I.; Maier, H.J. Martensite aging - Avenue to new high temperature shape memory alloys. Acta Mater. 2015, 89, 298-304. [CrossRef]

2. Picornell, C.; Pons, J.; Cesari, E. Stabilisation of martensite by applying compressive stress in Cu-Al-Ni single crystals. Acta Mater. 2001, 49, 4221-4230. [CrossRef]

3. Chernenko, V.A.; Pons, J.; Cesari, E.; Zasimchuk, I.K. Transformation behaviour and martensite stabilization in the ferromagnetic Co-Ni-Ga Heusler alloy. Scr. Mater. 2004, 50, 225-229. [CrossRef]

4. Kadletz, P.M.; Krooß, P.; Chumlyakov, Y.I.; Gutmann, M.J.; Schmahl, W.W.; Maier, H.J.; Niendorf, T. Martensite stabilization in shape memory alloys - Experimental evidence for short-range ordering. Mater. Lett. 2015, 159, 16-19. [CrossRef]

5. Eftifeeva, A.; Panchenko, E.; Chumlyakov, Y.; Maier, H.J. Two-way shape memory effect in [001] B2-oriented Co-Ni-Al single crystals. Mater. Today Proc. 2017, 4, 4789-4796. [CrossRef]

6. Panchenko, E.Y.; Timofeeva, E.E.; Larchenkova, N.G.; Chumlyakov, Y.I.; Tagiltsev, A.I.; Maier, H.J.; Gerstein, G. Two-way shape memory effect under multi-cycles in [001]-oriented $\mathrm{Ni}_{49} \mathrm{Fe}_{18} \mathrm{Ga}_{27} \mathrm{Co}_{6}$ single crystal. Mater. Sci. Eng. A 2017, 706, 95-103. [CrossRef]

7. Gerstein, G.; L'vov, V.A.; Kosogor, A.; Maier, H.J. Internal pressure as a key thermodynamic factor to obtain high-temperature superelasticity of shape memory alloys. Mater. Lett. 2018, 210, 252-254. [CrossRef]

8. Panchenko, E.; Eftifeeva, A.; Chumlyakov, Y.; Gerstein, G.; Maier, H.J. Two-way shape memory effect and thermal cycling stability in $\mathrm{Co}_{35} \mathrm{Ni}_{35} \mathrm{Al}_{30}$ single crystals by low-temperature martensite ageing. Scr. Mater. 2018, 150, 18-21. [CrossRef]

9. Timofeeva, E.E.; Panchenko, E.Y.; Pichkaleva, M.V.; Tagiltsev, A.I.; Chumlyakov, Y.I. The effect of stress-induced martensite ageing on the two-way shape memory effect in $\mathrm{Ni}_{53} \mathrm{Mn}_{25} \mathrm{Ga}_{22}$ single crystals. Mater. Lett. 2018, 228, 490-492. [CrossRef]

10. Panchenkoa, E.Y.; Timofeeva, E.E.; Chumlyakov, Y.I.; Osipovich, K.S.; Tagiltsev, A.I.; Gerstein, G.; Maier, H.J. Compressive shape memory actuation response of stress-induced martensite aged $\mathrm{Ni}_{51} \mathrm{Fe}_{18} \mathrm{Ga}_{27} \mathrm{Co}_{4}$ single crystals. Mater. Sci. Eng. A 2019, 746, 448-455. [CrossRef]

11. Panchenko, E.; Timofeeva, E.; Eftifeeva, A.; Osipovich, K.; Surikov, N.; Chumljakov, Y.; Gerstein, G.; Maier, H.J. Giant rubber-like behavior induced by martensite aging in $\mathrm{Ni}_{51} \mathrm{Fe}_{18} \mathrm{Ga}_{27} \mathrm{Co}_{4}$ single crystals. Scr. Mater. 2019, 162, 387-390. [CrossRef]

12. Ahlers, M.; Pelegrina, J.L. Ageing of martensite: Stabilisation and ferroelasticity in Cu-based shape memory alloys. Mater. Sci. Eng. A 2003, 356, 298-315. [CrossRef]

13. Ren, X.; Otsuka, K. Origin of rubber-like behaviour in metal alloys. Nature 1997, 389, 579-582. [CrossRef]

14. Otsuka, K.; Ren, X. Mechanism of martensite aging effects and new aspects. Mater. Sci. Eng. A 2001, 312, 207-218. [CrossRef]

15. Lauhoff, C.; Krooß, P.; Langenkämper, D.; Somsen, C.; Eggeler, G.; Kireeva, I.; Chumlyakov, Y.I.; Niendorf, T. Martensite aging in $\langle 001\rangle$ oriented $\mathrm{Co}_{49} \mathrm{Ni}_{21} \mathrm{Ga}_{30}$ single crystals in tension. Funct. Mater. Lett. 2018, 11, 1850024. [CrossRef]

16. Segui, C.; Cesari, E. Contributions to the transformation entropy change and influencing factors in metamagnetic Ni-Co-Mn-Ga shape memory alloys. Entropy 2014, 16, 5560-5574. [CrossRef]

17. Zhao, D.; Xiao, F.; Nie, Z.; Cong, D.; Sun, W.; Liu, J. Burst-like superelasticity and elastocaloric effect in [011] oriented $\mathrm{Ni}_{50} \mathrm{Fe}_{19} \mathrm{Ga}_{27} \mathrm{Co}_{4}$ single crystals. Scr. Mater. 2018, 149, 6-10. [CrossRef]

18. Nikolaev, V.I.; Yakushev, P.N.; Malygin, G.A.; Averkin, A.I.; Pulnev, S.A.; Zograf, G.P.; Kustov, S.B.; Chumljakov, Y.I. Influence of partial shape memory deformation on the burst character of its recovery in heated Ni-Fe-Ga-Co alloy crystals. Tech. Phys. Lett. 2016, 42, 399-402. [CrossRef]

19. Kustov, S.; Pons, J.; Cesari, E.; Van Humbeeck, J. Chemical and mechanical stabilization of martensite. Acta Mater. 2004, 52, 4547-4559. [CrossRef]

20. Beke, D.L.; Daróczi, L.; Tóth, L.Z.; Bolgár, M.K.; Samy, N.M.; Hudák, A. Acoustic emissions during structural changes in shape memory Alloys. Metals 2019, 9, 58. [CrossRef]

21. Pelegrina, J.L.; Ahlers, M. The martensitic phases and their stability in $\mathrm{Cu}-\mathrm{Zn}$ and $\mathrm{Cu}-\mathrm{Zn}-\mathrm{Al}$ alloys-I. The transformation between the high temperature $\beta$ phase and the 18R martensite. Acta Metall. Mater. 1992, 40, 3205-3211. [CrossRef] 
22. Chandrasekaran, M.; Cooreman, L.; Van Humbeeck, J.; Delaey, L. Martensitic transformation in Cu-Zn-Al: changes in transformation entropy due to post quench ageing in the $\beta$ or martensitic condition. Scr. Metall. 1989, 23, 239-273. [CrossRef]

23. Imano, Y.; Omori, T.; Oikawa, K.; Sutou, Y.; Kainuma, R.; Ishida, K. Martensitic and magnetic transformations of Ni-Ga-Fe-Co ferromagnetic shape memory alloys. Mater. Sci. Eng. A 2006, 438-440, 970-973. [CrossRef]

24. Bolgár, M.K.; Tóth, L.Z.; Szabó, S.; Gyöngyösi, S.; Daróczi, L.; Panchenko, E.Y.; Chumlyakov, Y.I.; Beke, D.L. Thermal and acoustic noises generated by austenite/martensite transformation in NiFeGaCo single crystals. J. Alloys Compd. 2016, 658, 29-35. [CrossRef]

25. Planes, A.; Macqueron, J.L.; Ortîn, J. Energy contributions in the martensitic transformation of shape-memory alloys. Philos. Mag. Lett. 1988, 57, 291-298. [CrossRef]

26. Beke, D.L.; Daróczi, L.; Elrasasi, T.Y. Determination of elastic and dissipative energy contributions to martensitic phase transformation in shape memory alloys. In Shape Memory Alloys-Processing, Characterization and Applications; Fernandes, F., Ed.; InTech: London, UK, 2013; p. 167. ISBN 978-953-51-1084-2.

27. Tóth, L.Z.; Daróczi, L.; Szabó, S.; Beke, D.L. Simultaneous investigation of thermal, acoustic, and magnetic emission during martensitic transformation in single-crystalline $\mathrm{Ni}_{2} \mathrm{MnGa}$. Phys. Rev. B 2016, 93, 144108. [CrossRef]

28. Rosinberg, M.L.; Vives, E. Metastability, Hysteresis, Avalanches, and Acoustic Emission: Martensitic Transitions in Functional Materials. In Disorder and Strain Induced Complexity in Functional Materials; Kakeshita, T., Fukuda, T., Saxena, A., Planes, A., Eds.; Springer Series in Materials Science; Springer: Berlin, Germany, 2012; Volume 148, pp. 249-272. ISBN 978-3-642-20943-7.

29. Planes, A.; Mañosa, L.; Vives, E. Acoustic emission in martensitic transformations. J. Alloys Compd. 2013, 577, S699-S704. [CrossRef]

30. Bonnot, E.; Vives, E.; Mañosa, L.; Planes, A.; Romero, R. Acoustic emission and energy dissipation during front propagation in a stress-driven martensitic transition. Phys. Rev. B 2008, 78, 094104. [CrossRef]

31. Mañosa, L.; Planes, A.; Rouby, D.; Morin, M.; Fleischmann, P.; Macqueron, J.L. Acoustic emission field during thermoelastic martensitic transformations. Appl. Phys. Lett. 1989, 54, 2574-2576. [CrossRef]

32. Gallardo, M.C.; Manchado, J.; Romero, F.J.; Del Cerro, J.; Salje, E.H.; Planes, A.; Vives, E.; Ricardo, R.; Marcelo, S. Avalanche criticality in the martensitic transition of $\mathrm{Cu}_{67.64} \mathrm{Zn}_{16.71} \mathrm{Al}_{15.65}$ shape-memory alloy: A calorimetric and acoustic emission study. Phys. Rev. B 2010, 81, 174102. [CrossRef]

33. Beke, D.L.; Bolgár, M.K.; Tóth, L.Z.; Daróczi, L. On the asymmetry of the forward and reverse martensitic transformations in shape memory alloys. J. Alloys Compd. 2018, 741, 106-115. [CrossRef]

34. Marcos, J.; Planes, A.; Manosa, L.; Casanova, F.; Battle, X.; Labarta, A.; Martinez, B. Magnetic field induced entropy change and magnetoelasticity in Ni-Mn-Ga alloys. Phys. Rev. B 2002, 66, 224413. [CrossRef]

35. Scruby, C.B. Quantitative acoustic emission techniques. In Research Techniques in Non-Destructive Testing; Sharpe, R.S., Ed.; Academic Press: London, UK, 1985; Volume III, ISBN 0126390533.

36. Zreihan, N.; Faran, E.; Vives, E.; Planes, A.; Shilo, D. Relations between stress drops and acoustic emission measured during mechanical loading. Phys. Rev. Mater. 2019, 3, 043603. [CrossRef]

37. Santamarta, R.; Cesari, E.; Font, J.; Muntasell, J.; Pons, J.; Dutkiewicz, J. Effect of atomic order on the martensitic transformation of Ni-Fe-Ga alloys. Scr. Mater. 2006, 54, 1985-1989. [CrossRef]

38. Khovailo, V.V.; Oikawa, K.; Abe, T.; Takagi, T. Entropy change at the martensitic transformation in ferromagnetic shape memory alloys $\mathrm{Ni}_{2+x} \mathrm{Mn}_{1-\mathrm{x}} \mathrm{Ga}$. J. Appl. Phys. 2003, 93, 8483-8485. [CrossRef]

(C) 2020 by the authors. Licensee MDPI, Basel, Switzerland. This article is an open access article distributed under the terms and conditions of the Creative Commons Attribution (CC BY) license (http://creativecommons.org/licenses/by/4.0/). 